\title{
SECONDARY REACTION ZONES IN COATED 4TH GENERATION NI-BASED BLADE ALLOYS
}

\author{
Aya Suzuki ${ }^{1}$, C. M. F. Rae ${ }^{1}$, M. Yoshida ${ }^{2}$, Y. Matsubara ${ }^{2}$ and H. Murakami ${ }^{2}$ \\ 1: Rolls-Royce UTP/University of Cambridge, Dept. of Mat. Sci. and Met, Pembroke Street, Cambridge, CB2 3QZ, UK \\ 2: Composite and Coatings Center, Natioanl Research Institute for Materials Science, 1-2-1 Sengen, Tsukuba Science City, Ibaragi, 305- \\ 0047, Japan
}

Keywords: PtAl, SRZ, Microstructure, Ni-base alloys

\begin{abstract}
The morphologies and growth kinetics of the Secondary Reaction Zone (SRZ) formed at the interface between the Pt-Aluminised coating and $4^{\text {th }}$ generation Ni-base superalloy substrates have been investigated. Three alloys with systematically varying Ru content in the range of $2-5 \mathrm{wt} \%$ were studied. Each alloy was tested using four different surface finishes prior to Pt coating. At the lowest Ru content sporadic formation of SRZ was observed, whilst in the higher Ru-containing alloys a continuous SRZ was formed. These alloys also showed more rapid SRZ growth, regardless of the original surface finish. The precipitation of TCPs in the substrate inhibited the growth of the SRZ towards the end of the exposure reversing the advantage of early nucleation. The volume fraction of the SRZ formation followed that in the substrate, reducing with $\mathrm{Ru}$ content. EBSD analysis revealed that the higher $\mathrm{Ru}$-containing alloys nucleate many more grains of the SRZ but the number of grains adjusts with growth towards a constant grain size. On balance $\mathrm{Ru}$ leads to a deeper penetration depth into the substrate.
\end{abstract}

\section{Introduction}

The formation of a Secondary Reaction Zone (SRZ) beneath an aluminised or Pt-Aluminised coating has the potential to reduce the effective cross section of a blade by in excess of $100 \mu \mathrm{m}$ or $10 \%$ of the wall thickness. The propensity to form such a layer is a sensitive function of composition and surface finish prior to coating [1]. Third generation alloys show a much increased formation of SRZ associated perhaps with the increased instability of such alloys with respect to the formation of Topological Close Packed phases (TCPs). By this logic the introduction of fourth generation alloys with the addition of ruthenium to increase the stability of the alloys [2-4] whilst maintaining the high rhenium content necessary for creep resistance, should reduce the thermodynamic driving force for the formation of SRZ. Whether or not this proves to be the case depends on the reasons for the stabilising effects of ruthenium.

The evaluation of the formation of SRZ is an essential part of the coating performance of the fourth generation alloys. In this paper we examine the effects of a systematic variation in the ruthenium content and the surface finish on the degradation of Pt-Aluminised coatings and the formation of the SRZ in particular. As part of this we measure the nucleation and growth kinetics of the SRZ and examine the crystallography and morphology of the phases involved. We note a distinct change in the morphology of the SRZ with composition: as the ruthenium content increases the nucleation rate increases to produce an even full layer. At lower ruthenium content the nucleation is more sporadic leading to a more uneven layer of SRZ.

\section{Experimental}

Nominal compositions of the fourth generation Ni-base single crystal superalloys are listed in Table I. Three fourth generation alloys were studied; these were identical in composition apart from a systematic variation in the ruthenium content from 2 to 5 wt.\%. The coatings were applied to surfaces cut normal to the bar axis, nominally [001]. Four surface finishes prior to coating were investigated: Ground (G), grit Blasted (B), Polished with 600 grade $\mathrm{SiC}$ paper (P) and Electropolished (EP). Hereafter, the surface finishes will be referred by the bracketed initials. Isothermal exposure tests were conducted at $1100^{\circ} \mathrm{C}$ for up to 500 $\mathrm{h}$, followed by cooling in air. The microstructure was investigated using SEM and EBSD. Pt-Aluminised coatings were applied using the low activity aluminising process RT22 for grit blasted specimens and by vapour aluminisation for the other finishes at $1100^{\circ} \mathrm{C}$.

Samples were examined after 20,50 and $500 \mathrm{~h}$ exposure and the thickness of the SRZ was measured to determine the growth of the SRZ. For this purpose the SRZ is defined as the region between the inter-diffusion zone, characteristically showing a high density of fine TCPS and a high angle boundary with the substrate as shown in Figure 1. For each specimen an average of 10 points was measured, depending the area fraction of SRZ. The measured values of the thickness were averaged, and standard deviation was used as an indication of the variability.

The area fraction of TCPs in the SRZ was measured to quantify the differences in TCP morphology in the Pt-Aluminised alloys. Square frames, $20 \mu \mathrm{m} \times 20 \mu \mathrm{m}$, were set onto images which had, by control of the image contrast, been turned to black and white. The 10 SRZ areas were chosen randomly. The area fraction of TCPs in SRZ was calculated by means of the histogram analysis function in Adobe Photoshop 7.0.

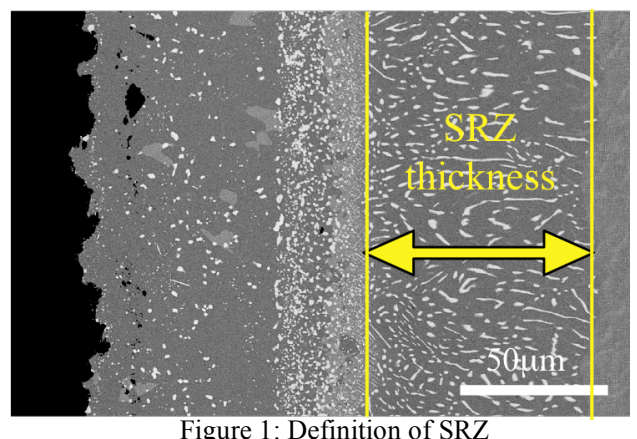

Table I: alloy composition

\begin{tabular}{c|cccccccccc}
\hline wt\% & Co & $\mathrm{Cr}$ & $\mathrm{Mo}$ & $\mathrm{W}$ & $\mathrm{Re}$ & $\mathrm{Ru}$ & $\mathrm{Al}$ & $\mathrm{Ta}$ & $\mathrm{Hf}$ & $\mathrm{Ni}$ \\
\hline \hline UCSX-2+2Ru & 8.0 & 3.0 & 1.0 & 8.0 & 6.5 & 2.0 & 5.4 & 8.0 & 0.1 & balance \\
UCSX-2+3Ru & 8.0 & 3.0 & 1.0 & 8.0 & 6.5 & 3.0 & 5.4 & 8.0 & 0.1 & balance \\
UCSX-2+5Ru & 8.0 & 3.0 & 1.0 & 8.0 & 6.5 & 5.0 & 5.4 & 8.0 & 0.1 & balance \\
\hline
\end{tabular}



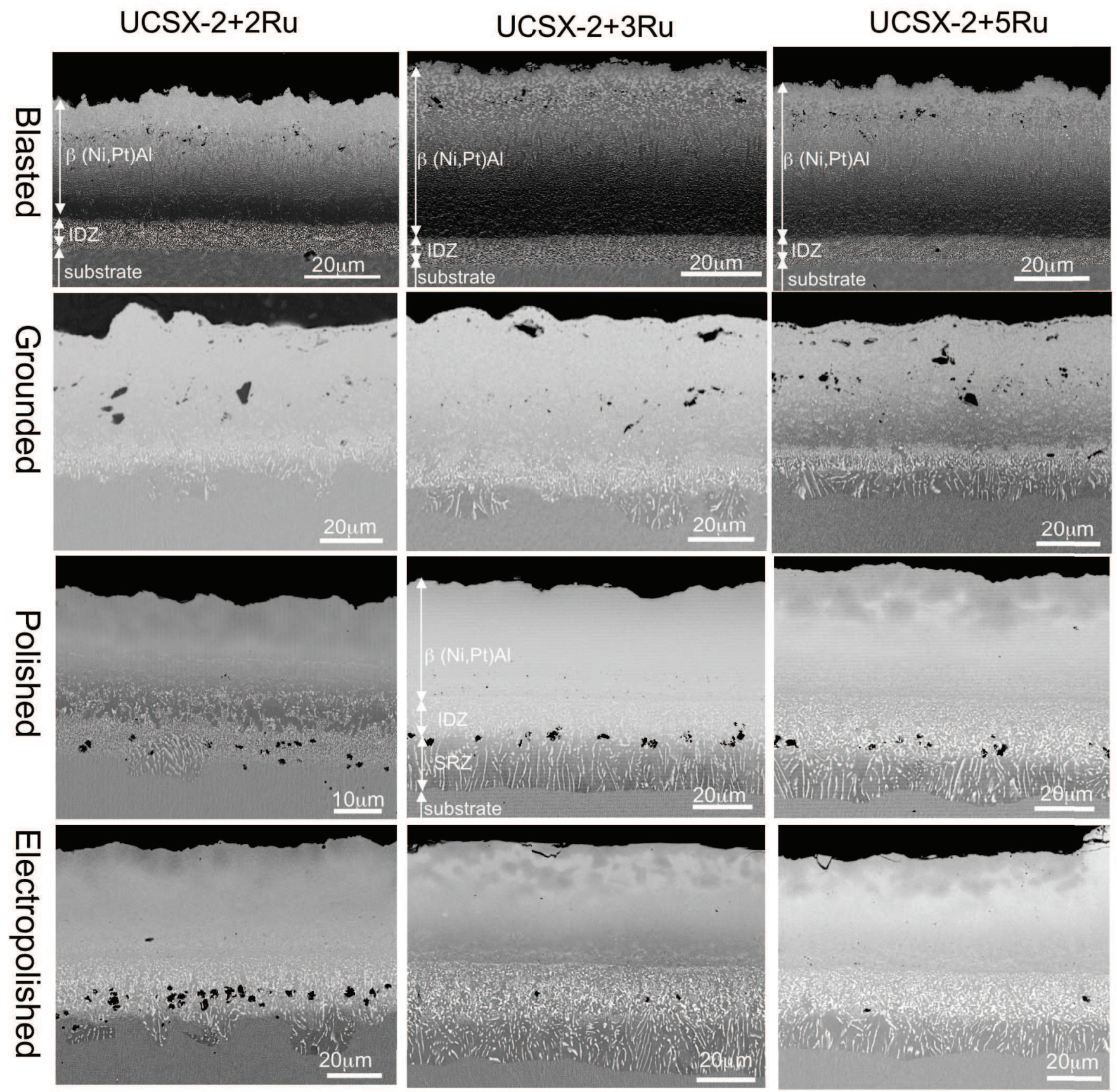

Figure 2: Microstructure of as aluminised specimens
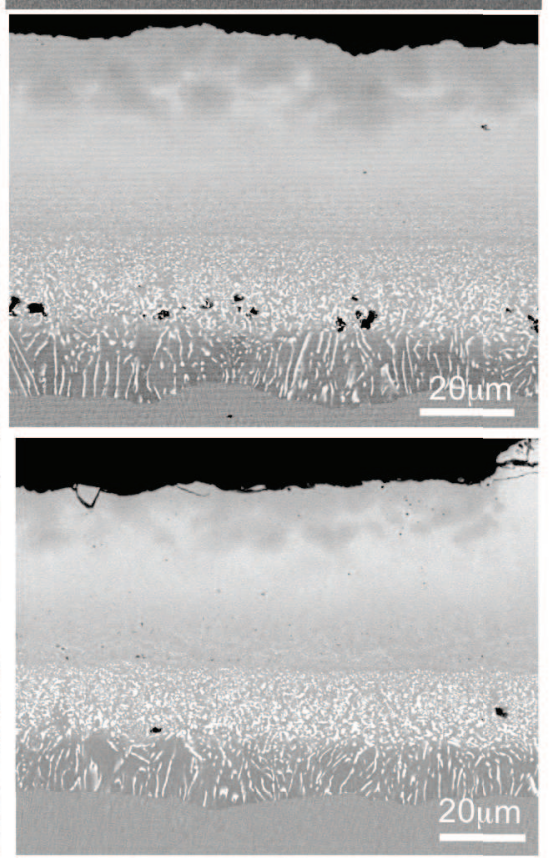

\section{Results}

\section{Microstructural evolution of specimens}

Figure 2 shows a montage of the microstructures of the as PtAluminised specimens. All the specimens consist of $\beta$ (Pt,Ni)Al surface layer, an Inter Diffus ion Zone (IDZ), and the substrate in that order. The vapor aluminised specimens had developed Secondary Reaction Zones (SRZ) during the $1 \mathrm{~h}$ heat treatment at $1100^{\circ} \mathrm{C}$ after aluminising, whereas the pack aluminised RT-22 (B) specimens did not show any SRZ. Little difference in the appearance of the specimens as a function of the surface finish was observed, but the alloy composition had a much greater effect. All the UCSX-2+2Ru samples showed sporadic SRZ formation, whereas the UCSX-2+3Ru and UCSX-2+5Ru specimens showed more continuous SRZ formation. This suggests that a higher amount of $\mathrm{Ru}$ in the substrate encourages SRZ nucleation at an early stage.

All of the vapour aluminised specimens had developed a continuous SRZ layer after only $20 \mathrm{~h}$ exposure, but the pack aluminised specimen were much slower to form the SRZ and after $50 \mathrm{~h}$ the UCSX $-2+2 \mathrm{Ru}$, shows only sporadic SRZ colonies in Figure 3. All samples of UCSX-2+2Ru showed extensive precipitation of TCPs in the substrate after just $20 \mathrm{~h}$. These are aligned regularly along the $<111>$ planes of the substrate and 

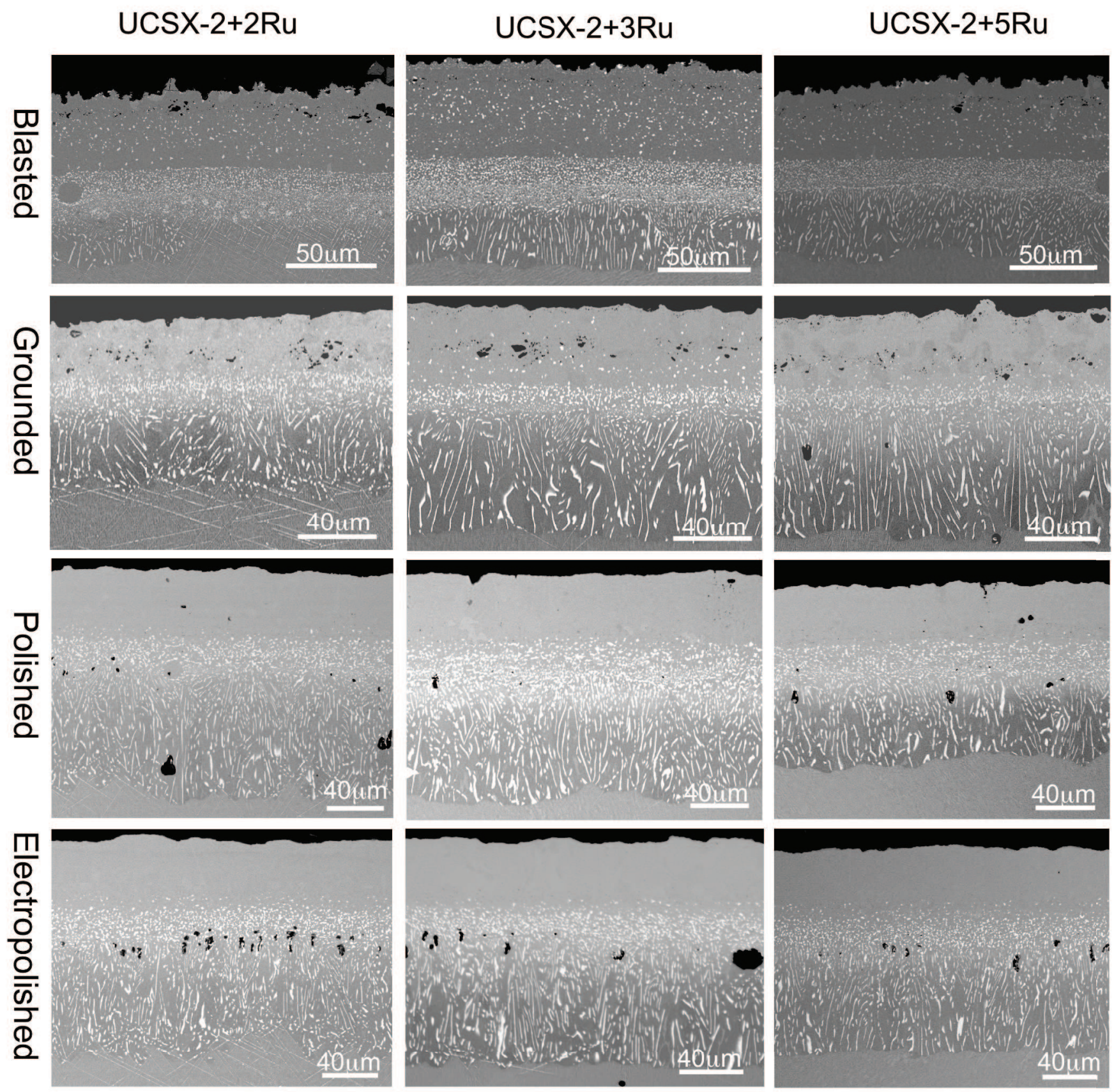

Figure 3: Microstructure of the specimens after $50 \mathrm{~h}$ isothermal exposure test

precipitate first in the Al-enriched substrate adjacent to the coating termed the Substrate Diffusion Zone (SDZ).

Figure 4 shows the microstructures after $500 \mathrm{~h}$ exposure. All the specimens have now developed a full SRZ layer and show profuse TCP precipitation in the SDZ. UCSX-2+2Ru in particular, showed the highest proportion of TCP phases in SDZ. Some of these TCP plates in the substrate are aligned with rows of incoherent precipitates in the SRZ indicating that the SRZ continues to grow after the TCPs form in the substrate. In other instances, TCP phases, precipitated in SDZ, prevent further growth of the SRZ. This seems to be the case where the TCP plate lies parallel to the boundary plane, as in Figure 5.
The higher Ru alloys, UCSX $-2+3 \mathrm{Ru}$ and UCSX $-2+5 \mathrm{Ru}$, showed more SRZ growth than UCSX-2+2Ru. At the same time, these two alloys showed less TCP precipitation in the SDZ than UCSX$2+2 \mathrm{Ru}$. There is hence a negative correlation between TCP precipitation in the substrate and SRZ formation.

As the $\mathrm{Ru}$ content increases there is a marked decrease in the formation of voids in the IDZ at the root of the SRZ; this is most apparent between 20 and $50 \mathrm{~h}$, Figure 3. After $500 \mathrm{~h}$ these had largely filled and disappeared in the vapour aluminised samples (G, P, EP) but are retained in the pack aluminised samples (B). The number of voids at the root of the SRZ also decreases with prior surface damage; i.e. in the order $\mathrm{G}<\mathrm{P}<\mathrm{EP}$. Again this occurs in the first 20 - 50 hours of exposure, Figure 3. 
UCSX-2+2Ru
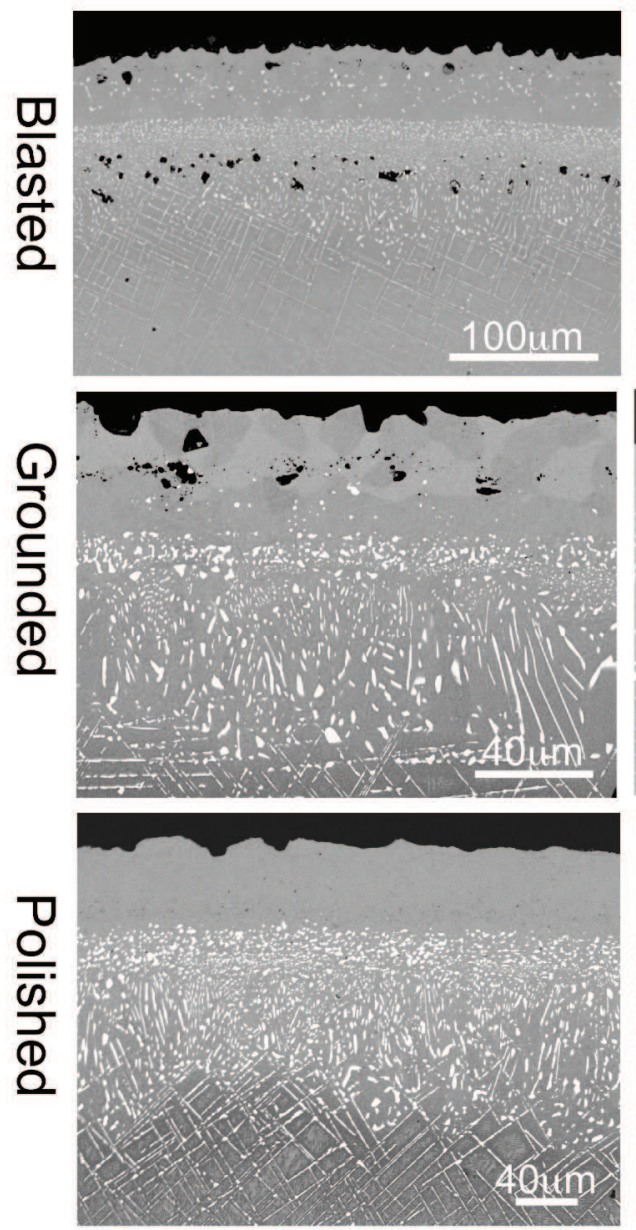

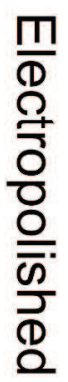
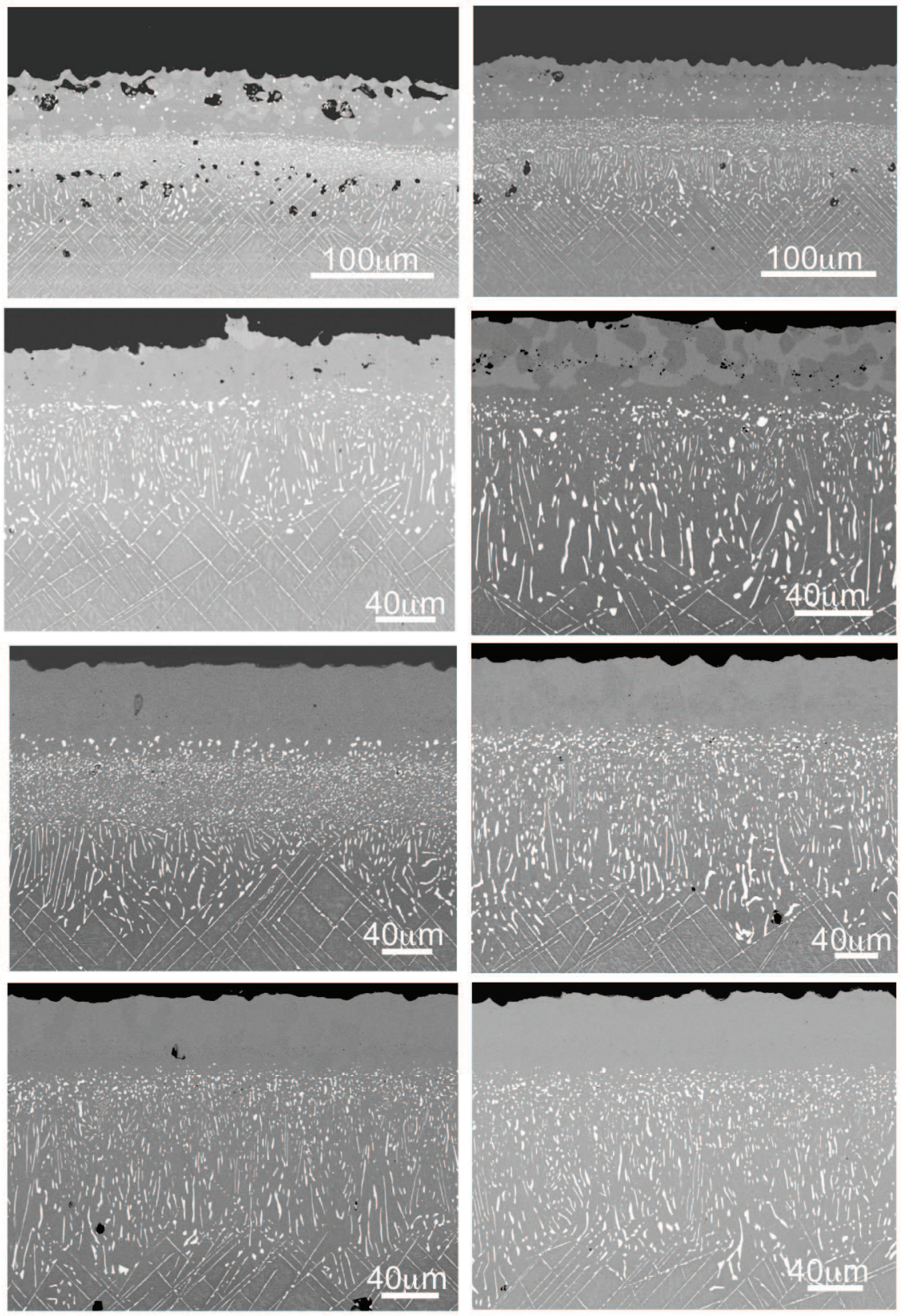

Figure 4: Microstructure of the specimens after 500h isothermal exposure test

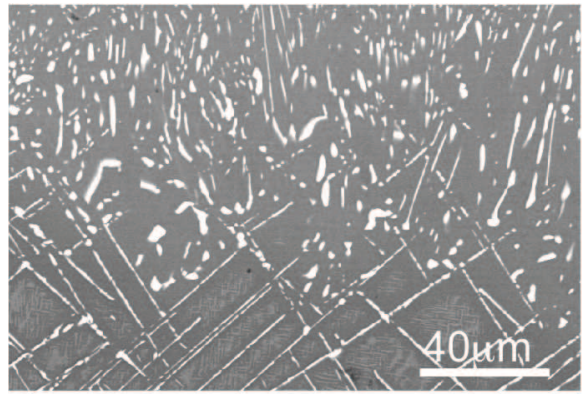

Figure 5: Enlarged microstructure of interface between SRZ and SDZ in $\mathrm{UCSX}-2+2 \mathrm{Ru}(\mathrm{P})$ after $500 \mathrm{~h}$ exposure

\section{Microstructural Evolution of the SRZ and the SDZ}

Figure 6 shows the growth kinetics of the SRZ in each specimen during the first $500 \mathrm{~h}$ exposure. Quantifying the SRZ thickness reveals a numbers of interesting trends. Contrary to expectations the Polished (P) and Electropolished (EP) specimens showed the highest rate of SRZ formation; there was little difference between the behaviour of the two finishes. In all alloys the Pack aluminised coatings (B) are very much slower to form SRZ and once formed, the thickness of the SRZ remains below of the other specimens. In the alloy UCSX-2+2Ru the SRZ ceases to grow after about $50 \mathrm{~h}$ exposure for the vapour aluminised specimens regardless of 
(a)

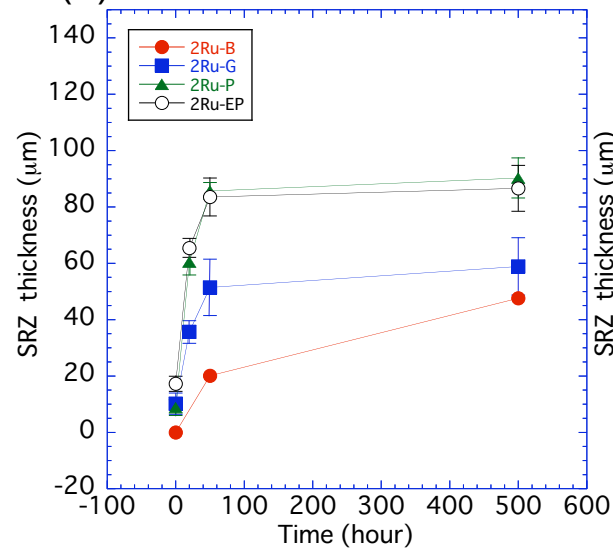

(b)

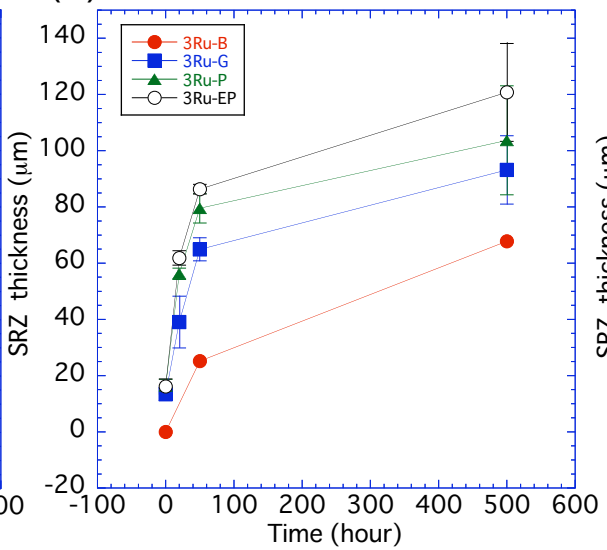

(c)

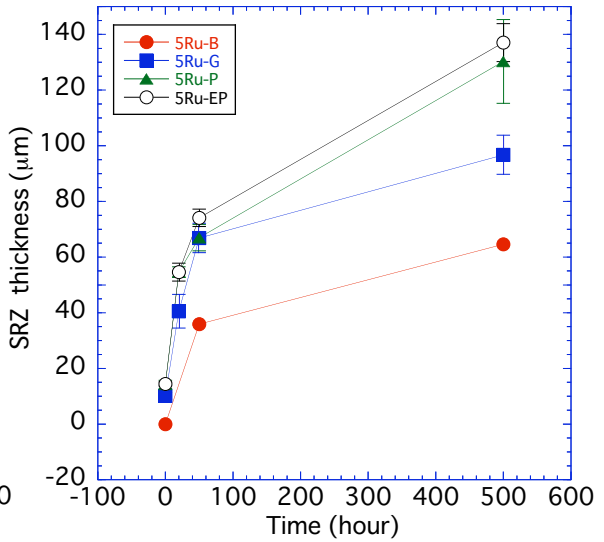

Figure 6: SRZ growth kinetics of (a) UCSX-2+2Ru, (b) UCSX-2+3Ru, and UCSX-2+5Ru. (B: Blasted, G: Ground, P: Polished, EP: Electropolished Specimens.)
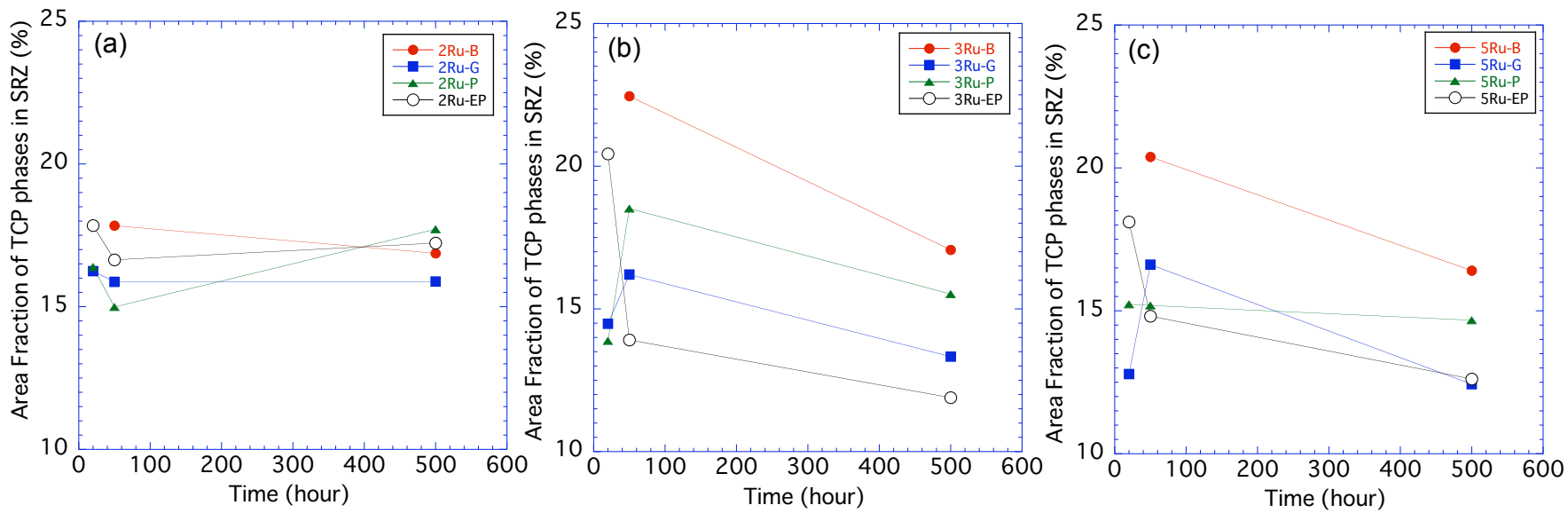

Figure 7: TCP phase area fraction of (a) UCSX-2+2Ru, (b) UCSX-2+3Ru, and UCSX-2+5Ru in SRZ. (B: Blasted, G: Ground, P: Polished, EP: Electropolished Specimens.)

surface finish. The SRZ in alloys UCSX-2+3Ru and UCSX$2+5 \mathrm{Ru}$ continues to grow substantially after $50 \mathrm{~h}$.

The TCP area fraction in the SRZ is plotted in Figure 7. In UCSX$2+2 \mathrm{Ru}$, area fraction changes little with either time or surface finish. In the other two alloys with the higher Ru content the TCP fraction tends to decrease with time, albeit after a small initial rise for the two rougher finishes. The pack aluminised sample (B) shows some distinctive differences. The growth rate of the SRZ for (B) is consistently lower for all the alloys and generally shows a much higher TCP volume fraction.

Figure 8 shows EBSD mappings and the corresponding pole figures for typical SRZ areas between the IDZ and the substrate. The normal to the coated surface for all the alloys lies within $20^{\circ}$ of the [001] direction, but the sections were cut at various angles giving a variety of substrate orientatiois perpendicular to [001] in Figure 8 . For the contrary, the [001] pole figures have in all cases been rotated to locate the substrate [001] orientation normal to the page and the [100] and [010] orientations along the $\mathrm{x}$ and $\mathrm{y}$ axes. Three surface finishes of the UCSX-2+2Ru alloys are presented in the first three maps (Figures 8 (a)-(c)), and the three alloys in the Polished state in the last three maps (Figures 8 (c)-(f)). This allows comparison between both surface finish and alloy composition. Only results for the vapour aluminised coatings $(\mathrm{G}$, $\mathrm{P}$, and EP) are presented. The black areas correspond to the TCP phases which were generally not recognized by the software under the conditions used for mapping. Careful spot analysis using EBSD patterns enabled the TCP phases in the SRZ to be identified as $\mathrm{P}$ phase.

The number of SRZ grains nucleated during the early stages of growth varies greatly with both surface finish and alloy content. This has been quantified by counting the number of grains at the root of the SRZ adjacent to the coating and at the end of the SRZ adjacent to the substrate. A straight line was drawn at each location and all orientations where two or more adjacent points were indexed were included; the results are given in Table II. Comparing first the effect of the different surface finishes in the $2 \% \mathrm{Ru}$ alloy: there is a consistent increase in the number of distinct orientations of grains at the root of the SRZ as the degree of roughness of the surface increases in the order $\mathrm{EP}<\mathrm{P}<\mathrm{G}$. Interestingly, as the SRZ grows the numbers of grains increases further and by the time the test was interrupted at $20 \mathrm{~h}$ the results are quite similar with the number grains multiplying by almost a factor of two in the case of the Electropolished sample but by less than $10 \%$ for the Ground specimen. Although it showed the highest nucleation rate, the Ground specimen penetrated least into the substrate as shown in the graphs in Figure 6. The Ground specimen was also unusual in showing areas with the substrate orientation at the root of the SRZ indicating that these areas have not been traversed by a high angle boundary. 
(a)

\section{Example}

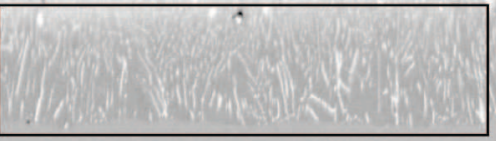

50

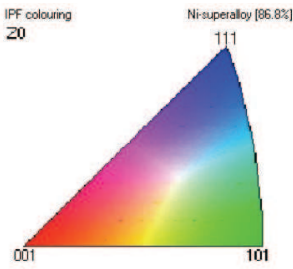

(b)
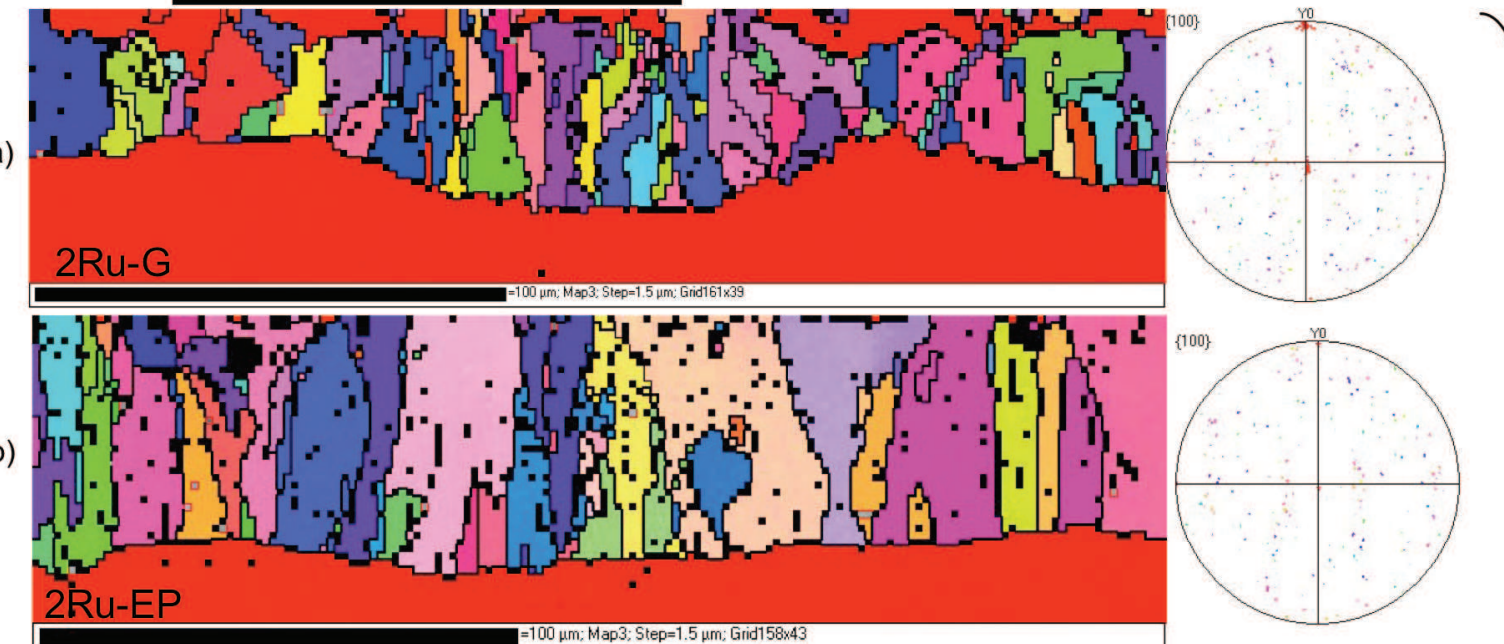

(c)
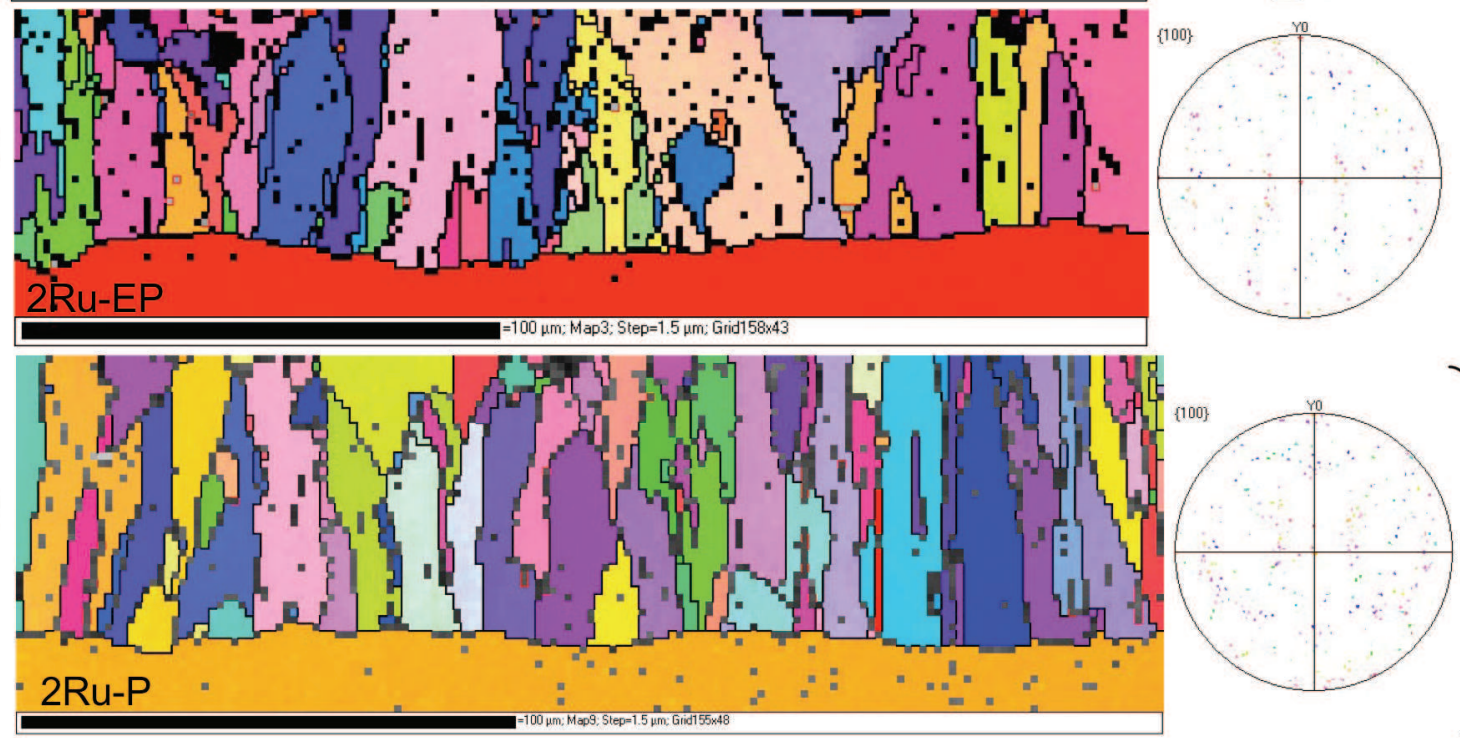

Surface finish

(d)
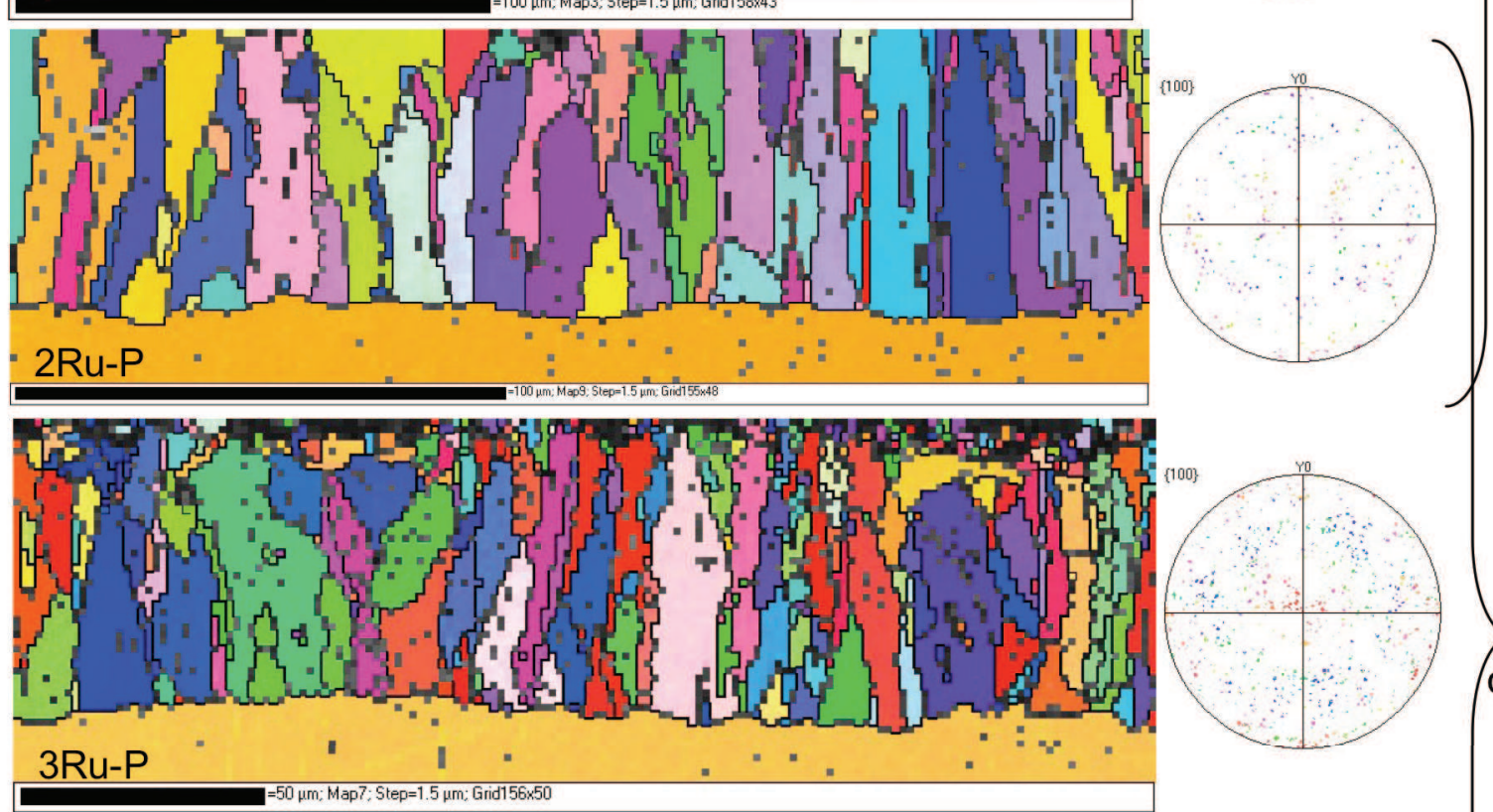

Alloy composition

(e)
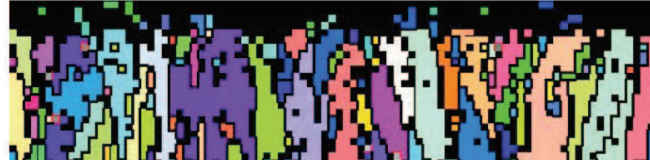

e)
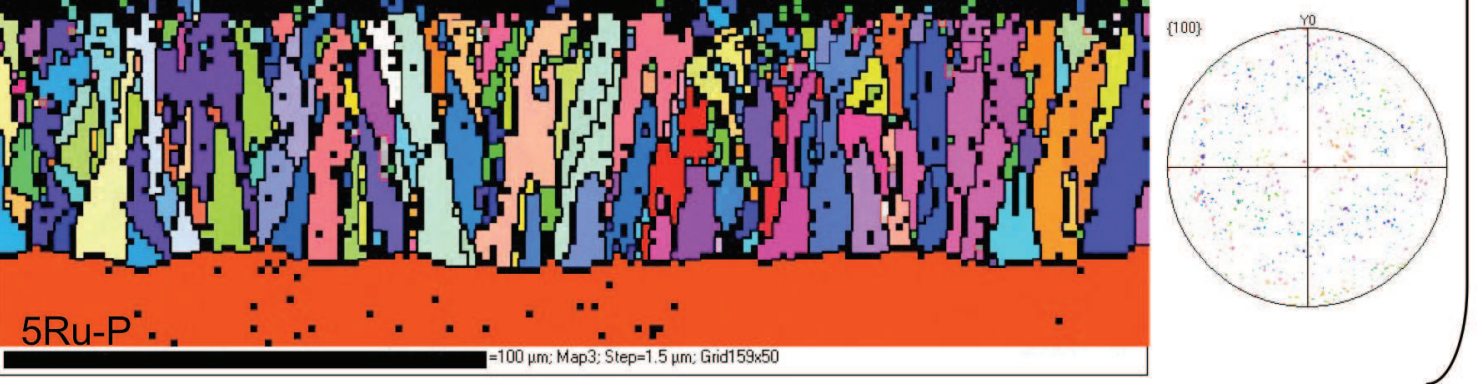

Figure 8: EBSD mapping and pole figures of (a) Grounded UCSX-2+2Ru, (b) Electropolished UCSX-2+2Ru, (c) Polished UCSX-2+2Ru, (d) Polished UCSX-2+3Ru, and (e) Polished UCSX-2+5Ru after the exposure of $20 \mathrm{~h}$ 
Table II: Number of grains in $150 \mathrm{~mm}$ straight line section as shown in Figure 8.

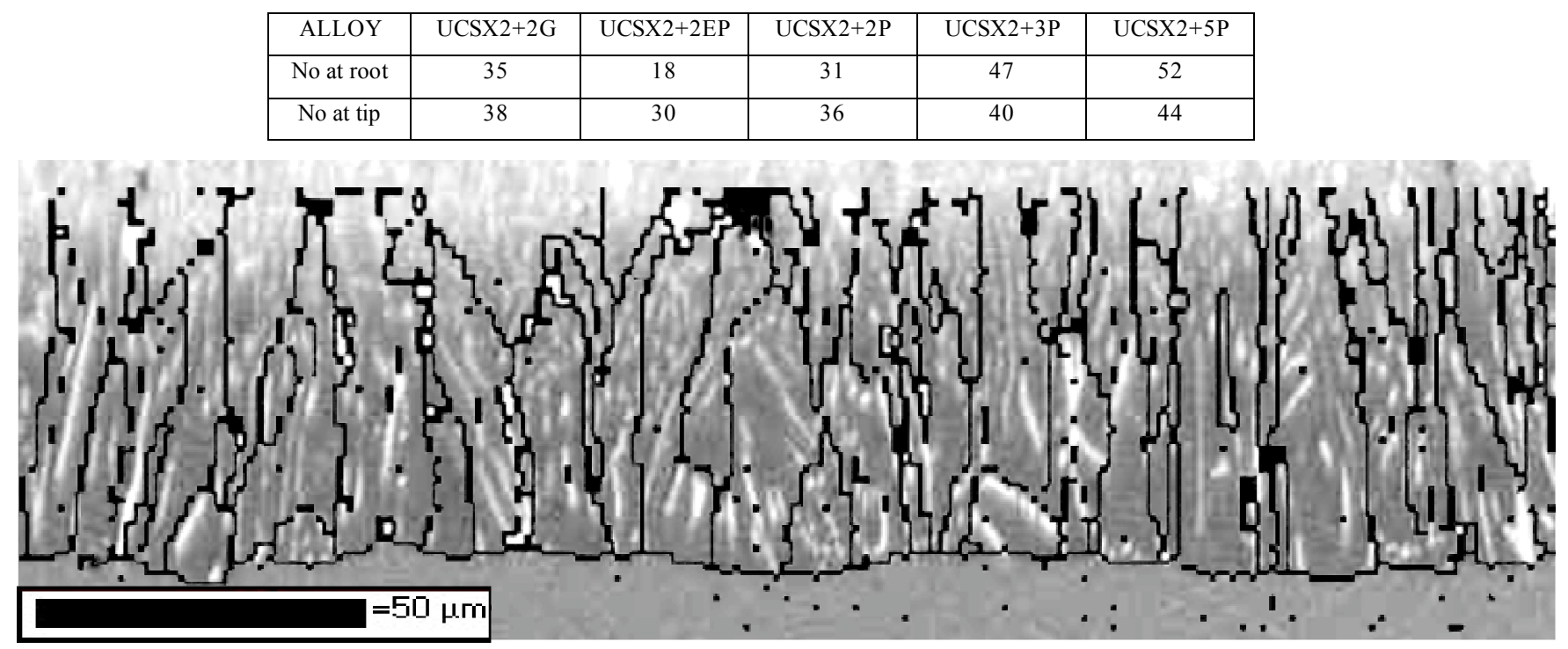

Figure 9: Backscattered images of Electropolished UCSX-2+2Ru overlaid with the EBSD grain map after 20h exposure at $1100^{\circ} \mathrm{C}$

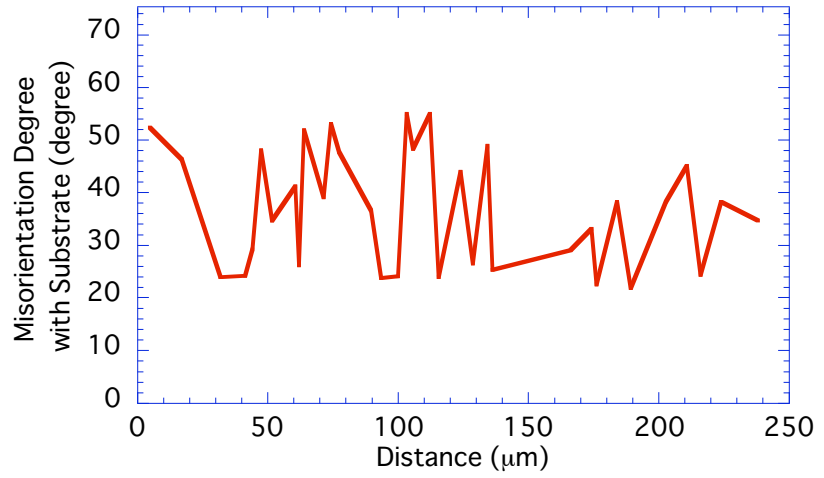

Figure 10: Misorientation degree of SRZ grain with substrate in Electropolished UCX-2+2Ru after $20 \mathrm{~h}$ exposure at $1100^{\circ} \mathrm{C}$

Turning to the effect of the $\mathrm{Ru}$ content of the alloys, there is a clear effect of the higher Ru content resulting in a much higher nucleation rate, for example the number of grains increases by nearly $70 \%$ from the $2 \% \mathrm{Ru}$ alloy to the $5 \% \mathrm{Ru}$ alloy. But, as observed in the surface finish results, the number of grains converges on a similar number as the SRZ grows with the $2 \% \mathrm{Ru}$ alloy nucleating further grains and the $5 \% \mathrm{Ru}$ alloy losing some orientations.

Figure 9 shows a backscattered image of Electropolished UCSX$2+2 \mathrm{Ru}$ overlaid with the EBSD grain outline map. It appears that in all cases the distribution of orientations shows no particular texture with the distribution of the poles of the SRZ grains fairly evenly distributed over the stereographic triangle. Examination of the boundary orientations with respect to the substrate showed them all to be high angle boundaries for example Figure 10 shows the Electropolished UCSX-2+2Ru after $20 \mathrm{~h}$ exposure. The angle of misorientation between the grains and the substrate all lie in the range of $20^{\circ}-60^{\circ}$; approximately $40 \%$ between $20^{\circ}-30^{\circ}$. No preferred high mobility misorientation could be detected consistent with the lack of texture in the SRZ. It is interesting to use that the [001] orientation of the coated sample used in this work was found previously to be resistant to the formation of SRZ in the alloy TMS-82+, coated with MCrAlY[5].About $20 \%$ of the boundaries between the individual grains were twin boundaries; twining is clearly a potential mechanism for the generation of new orientations observed in some samples.

\section{Discussion}

The compatibility of coatings of various types is an important factor in the development of fourth generation alloys. In order to utilize fully the strength of these alloys blade designs require thin sections. Thus it is important to maintain the structural integrity of the alloy throughout the section by minimising the width disrupted by inter-diffusion with the coating. The effect of $\mathrm{Ru}$ on the formation of SRZ is an issue of importance to the alloy developer. In this study the concentration of $\mathrm{Ru}$ was varied over the range found necessary to effectively suppress the formation of TCP phases in the substrate $[2,6]$ whilst keeping the cost of the alloy within reasonable bounds and avoiding the formation of the delta phase [7]. Observations in the substrate indicate that the $\mathrm{Ru}$ is successful in suppressing the formation of TCPs with the $5 \%$ alloy showing very little TCP formation after exposures of $500 \mathrm{~h}$. It has been argued that this is due to a combination of an increasing $\gamma$ volume fraction and a decreasing growth rate of the TCPs $[8,9]$. In ref. 7 the Ru-containing alloy was prepared by adding $\mathrm{Ru}$ to an existing alloy SRR300D, reducing the volume fraction of $\gamma^{\prime}$ and helping to stablise the alloy. Here the $\mathrm{Ru}$ is substituted for $\mathrm{Ni}$ and the predictions from the proprietary software J Mat Pro [10] predict a slight increase in the volume fraction of the $\gamma^{\prime}$ precipitates with increasing $\mathrm{Ru}$ content, Table III. In the SDZ aluminium diffusion from the coating reduces and eliminates the $\gamma$ phase, hence the formation of TCP phases depends only on the solubility of the TCP elements in the $\gamma^{\prime}$ phase. The SDZ adjacent to the SRZ in the formation of TCPs is prolific in all alloys after $500 \mathrm{~h}$.

The formation of the SRZ involves the nucleation of grains of a distinct orientation and their subsequent migration into the substrate by the passage of a high angle grain boundary. The boundary provides a fast diffusion path enabling the 
Table III: Predicted phase volume fractions using J Mat Pro [10] firstly including all phases and secondly excluding the TCP phases to simulate the initial structure of the alloy.

\begin{tabular}{|c|c|c|c|c|c|c|}
\hline Alloy & \multicolumn{2}{|c|}{ Phase volume fractions (\%, Including TCP phases) } & \multicolumn{2}{c|}{ Excluding TCP phases } \\
\hline & $\gamma$ & $\gamma^{\prime}$ & $\mathrm{P}$ & $\mu$ & $\gamma$ & $\gamma^{\prime}$ \\
\hline UCSX2+2Ru & 43.4 & 48.4 & 0.5 & 7.7 & 53.3 & 46.7 \\
\hline UCSX2+3Ru & 42.7 & 48.8 & 2.3 & 6.9 & 53.1 & 46.9 \\
\hline UCSX2+5Ru & 41.2 & 49.6 & 7.1 & 2.1 & 52.7 & 47.3 \\
\hline
\end{tabular}
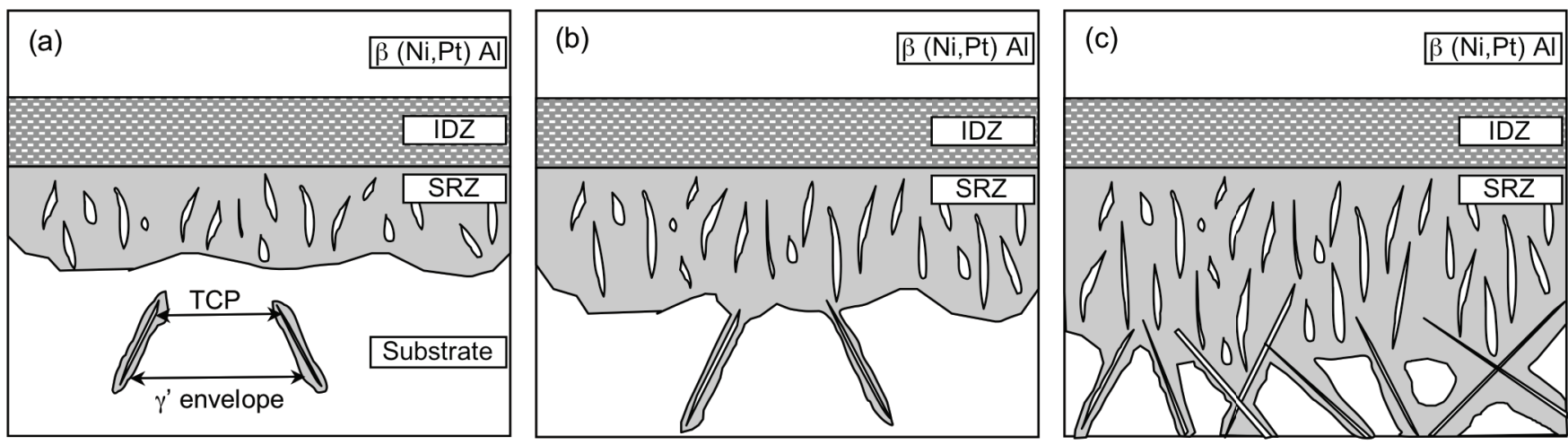

Figure 11: Schematic diagrams of the SRZ growth mechanism and the interaction with TCP growth in the substrate, (a) Stage I: TCPs nucleate in the aluminium enhanced substrate (SDZ) and grow with an envelope of $\gamma^{\prime}$ as the aluminium is rejected from the TCPs, (b) Stage II: the TCPs reach the high-angle grain boundary of the SRZ and become incorporated in the SRZ, (c) Stage III: as the density of TCPs in the substrate increases they act as a physical barrier to further growth of the SRZ.

rationalization of the fine $\gamma / \gamma^{\prime}$ microstructure of the substrate to a lower-energy, coarser morphology and at the same time the precipitation of the TCP phases at approximately equilibrium volume fractions for the local composition. This is, of course, modified by the diffusion of the $\mathrm{Al}$ into the substrate which varies throughout the exposure. SRZ formation is thus a discontinuous precipitation process.

The sections which follow compare the three vapour aluminised samples as a function of the $\mathrm{Ru}$ content, the surface finish and finally, the pack aluminised samples with the vapour aluminised samples.

\section{The effect of Ru on SRZ morphology and growth}

$\mathrm{Ru}$ increases the thickness of the SRZ for the vapour aluminised samples but has little effect on the pack aluminised samples. The pack aluminised samples show significantly different behaviour and will be discussed separately in the next section. In the first 50 hours SRZ grows in all three alloys at about the same rate but after that time growth continues in the $3 \%$ and the $5 \%$ alloy but not the $2 \%$ alloy. The volume fraction of TCPs remains stable in UCSX-2+2Ru after $50 \mathrm{~h}$ but drops in the other two alloys as SRZ continues to grow. The continuous growth of the SRZ facilitates the diffusion of $\mathrm{Al}$ into the substrate thus reducing the $\mathrm{Al}$ levels in the SRZ and increasing the proportion of $\gamma$. This allows some of the TCPs to dissolve leading to the measured reduction in the TCP volume fraction in the SRZ in UCSX-2+3Ru and UCSX-2+5Ru after 500 h, Figure 4.

There is a significant increase in the nucleation rate as the $\mathrm{Ru}$ content increases as shown by the very large numbers of grains at the root of the SRZ in UCSX-2+3Ru and UCSX-2+5Ru. The lowest $\mathrm{Ru}$ alloy UCSX-2+2Ru was the only sample to show evidence of retained substrate between the coating and the SRZ, in all other cases the SRZ nucleated directly below the NiAl coating. It is not clear why this occurs but may reflect an increased driving force for the formation of the SRZ with $\mathrm{Ru}$ content. We also observe a decrease in the void formation with $\mathrm{Ru}$ which is most evident in the Electropolished specimen and this may be due to the reduced number of grain boundaries in the lower Ru alloy as these would be able to act as sinks for excess vacancies generated by an imbalance in diffusion.

It was expected that the number of grains in the SRZ would decrease as growth competition between the grains selected those with the boundary misorientation which had the greatest mobility. This does not appear to be the case; the number of grains increased or decreased towards a constant value. At the outer edge of the SRZ the average width of a grain is about $6 \mu \mathrm{m}$, very similar to the spacing of the TCPs. Figure 9 shows a backscattered image of Polished UCSX-2+2Ru overlaid with the EBSD grain outline map. Growth of the TCPs is analogous to eutectoid precipitation with the TCPs lying approximately parallel to the growth direction, and it can be seen that the TCP phases frequently lie at the boundaries between the grains. It seems as if the width of a grain is determined by the spacing of the TCP precipitates. This, in turn, should be a compromise between the diffusion distance along the moving boundary and the minimization of the interphase boundary energy between the $\gamma^{\prime}$ and the TCPs. As the volume fractions of the TCPs for the Polished specimens are all approximately $15 \%$ after $20 \mathrm{~h}$ it is understandable why the spacing of the grains adjusts to a similar value in all the specimens.

All the boundaries between the SRZ and the substrate were high angle boundaries with misorientation between $20^{\circ}-60^{\circ}$, consistent with the report by Lavigne [11]. Hence some selectivity in either nucleation or growth in the very early stages of the SRZ formation has occurred to eliminate the less mobile lower angle boundaries. 
We observe a clear increase in the number of grains nucleated as the $\mathrm{Ru}$ content increases. However this is associated with a lower growth rate of the SRZ in all alloys particularly in the first $50 \mathrm{~h}$ exposure. The same effect is seen with respect to the surface damage: the depth of the SRZ at both $20 \mathrm{~h}$ and $50 \mathrm{~h}$ reduces as the surface damage increases $(\mathrm{G}>\mathrm{P}>\mathrm{EP}$ ), and the grain size of the SRZ decreases, Table II. It is not clear that the grain size is necessarily the cause of the lower growth rate, merely that lower growth rate is associated with a smaller grain size resulting either from high surface damage or high $\mathrm{Ru}$ content. Further investigations are required to differentiate these effects.

The mechanism by which the number of grains reduces is clear: some orientations simply become occluded by others, particularly where these are separated by a TCP plate. But the mechanism by which the number of grains increases is less obvious; one possibility is simply the nucleation of new orientations by the formation of twins which form $20 \%$ of boundaries between SRZ grains. This is the subject of further work.

Observation of the samples after $50 \mathrm{~h}$ identifies another indirect effect of the substrate composition on the depth of the SRZ. After $50 \mathrm{~h}$ the alloy UCSX-2+2Ru is precipitating TCP phases in the substrate adjacent to the SRZ. After $500 \mathrm{~h}$ all three alloys show TCPs in the substrate with the highest density in the low Ru alloy as expected. The formation of a TCP in the substrate with its associated envelope of $\gamma^{\prime}$ will reduce the driving force for SRZ growth [12], but it can also physically prevent further growth of the SRZ where the plane of the TCP plate lies at a shallow angle to the interface between the SRZ and the substrate, Figure 11. Where the needle impinges on the interface at an angle close to $90^{\circ}$ the interface grows through the needle incorporating it into the SRZ as shown by the line of incoherent precipitates in the SRZ but lying in line with the coherent precipitate in the substrate, Figure 5. Hence the TCPs physically inhibit further SRZ growth as is observed in Figure 6 and this effect will be greatest in the lower $\mathrm{Ru}$ alloy UCSX-2+2Ru, which has the highest volume fraction in the substrate. As the appearance of a substantial density of precipitates after $50 \mathrm{~h}$ in the substrate (Figure 3) coincides with the plateau in the SRZ thickness in the lowest Ru alloy, (Figure 6(a)) it is reasonable to assume that TCP precipitation is inhibiting further development of the SRZ. Once the SRZ stops growing the volume fraction of TCPs stabilises, Fig. 7 (a).

\section{Effect of surface finish on SRZ morphology and growth}

Walston [1] reported that surface residual stress has a large effect on the formation of the SRZ, and suggested that electropolishing prior to Pt coating is an effective way of eliminating the SRZ. In this study the effect of surface finish was less dramatic than that of alloy composition. The blasted specimens were coated by a RT22 pack aluminisation process and will be discussed separately in the next section, as the aluminisation process appears to have a much greater influence on SRZ formation than the surface finish.

The SRZ is not removed by electropolishing, but a clear link between the surface finish and the number of nuclei formed is established with a halving of the number of nuclei formed in the Electropolished specimen when compared to the Ground finish. The effect of decreased surface roughness in retarding the growth rate is not confirmed, indeed quite the opposite; the Ground specimen with the roughest surface finish shows the lowest growth rate of all the vapour aluminised samples in each alloy, Figure 6. It would seem that the driving force for the discontinuous precipitation process is high in these alloys, causing nucleation in the absence of deformation. Once SRZ grains are formed, the size adapts towards a common value of about $6 \mu \mathrm{m}$. The effect is most obvious in the Electropolished sample where the sporadic nucleation at the root of the SRZ is followed by the generation of new grains almost doubling the number of grains. It is expected that this process will continue after $20 \mathrm{~h}$ until the number of grains is the same as for the other two surface finishes. Growth rates in the Electropolished sample are consistently the fastest in all three alloys. Hence it seems that where the propensity to form the SRZ is strong, surface finish is not an effective way of reducing the impact of the SRZ on the substrate.

Observations on the difference between Pack and Vapour aluminisation.

The samples which had been grit blasted and pack aluminised show a consistently lower penetration of the SRZ into the substrate in all of the alloys. Irrespective of surface finish, within the SRZ the volume fraction of TCPs is higher in the pack aluminised samples. The temperature of the vapour aluminising process $\left(1100^{\circ} \mathrm{C}\right)$ is substantially higher than the pack aluminising process RT22 $\left(\sim 900^{\circ} \mathrm{C}\right)$ and results in the formation of some SRZ in all three alloys. This may explain the early differences between the two processes but does not explain why the SRZ does not continue to grow. One possibility is the formation of precipitates in the substrates of all the alloys inhibiting further growth. The difference between the two finishes is of considerable significance as aluminised coatings are increasingly applied by a vapour processes. Further work continues to investigate these differences.

\section{Conclusions}

Secondary Reaction Zones in Pt-Al coated $4^{\text {th }}$ generation Ni-base blade alloys were investigated, and following sequences are obtained.

- $\mathrm{Ru}$ is effective in inhibiting TCP formation in substrate, but promotes greater SRZ formation.

- TCP precipitation in the substrate inhibits SRZ growth.

- Higher Ru resulted in an increased nucleation rate of the SRZ.

- The size of the individual grains in the SRZ varies throughout growth, reducing or increasing towards a particular value determined by the spacing of the TCPs in the SRZ.

- $\quad$ Surface damage has an effect of increasing the nucleation of the SRZ but the growth rate and penetration depth is larger for the Electropolished specimens.

- Pack aluminisation leads to reduced SRZ penetration in all alloys.

\section{Acknowledgement}

The authors would like to thank Dr R.A. Hobbs, Dr. N. Jones, and Dr. B. Broomfield in Rolls-Royce plc for providing materials and fruitful discussion. Also, provision of laboratory facilities from the University of Cambridge is acknowledged. 


\section{Reference}

[1] W. S. Walston, J. C. Schaeffer and W. H. Murphy: "A new type of microstructural instability superalloys -SRZ" Superalloys 1996, Edited by R. D. Kissinger, D. J. Deye, D. L. Anton, A. D. Cetel, M. V. Nathal, T. M. Pollock and D. A. Woodford, TMS, Warrendale PA, 1996, 9-18

[2] K. S. O'Hara, W. S. Walston, E. W. Ross, and R. Darolia: "Ni base superalloy and article", US5482789. Patent, USA, January 1996.

[3] S. Tin, A. C. Yeh, A. P. Ofori, R. C. Reed, S. S. Babu, and M. K. Miller: "Atomic partitioning of ruthenium in Ni-based superalloys", Superalloys 2004, Edited by K. A. Green, T. M. Pollock, H. Harada, T. E. Howson, R. C. Reed, J. J. Schirra and W. S. Walston, TMS, Warrendale PA, 2004, 735-742.

[4] R. A. Hobbs, S. Tin, C. M. F. Rae, R. W. Broomfield, and C. J. Humphreys: "Solidification characteristics of advanced nickel-base single crystal superalloys", Superalloys 2004, Edited by K. A. Green, T. M. Pollock, H. Harada, T. E. Howson, R. C. Reed, J. J. Schirra and W. S. Walston, TMS, Warrendale PA, 2004, 819-826.

[5] T. Sakai, M. Shibata, H. Murakami, and S. Kuroda: "Microstructural investigation of CoNiCrAlY coated Nibased single crystal superalloy prepared by LPPS", Material Transactions, Vol. 47, No. 7, 2006, 1665-1670

[6] W. S. Walston, A. Cetel, R. MacKay, K. O’Hara, D. Duhl and R. Dreshfield: "Joint development of a fourth generation single crystal superalloys", Superalloys 2004, Edited by K. A. Green, T. M. Pollock, H. Harada, T. E. Howson, R. C. Reed, J. J. Schirra and W. S. Walston, TMS, Warrendale PA, 2004, 15-24

[7] B. Tryon and T. M. Pollock: "Experimental assessment of Ru-Al-Ni ternary phase diagram at 1000 and $1100^{\circ} \mathrm{C}$ ", Materials Science and Engineering A, 430A, 2006, 266-276

[8] A. C. Yeh: "High temperature phase stability and creep of Ru-bearing Ni-based single crystal superalloys", $P h D$ thesis, University of Cambridge, 2005

[9] R. A. Hobbs, L. Zhang, C. M. F. Rae, and S. Tin: "Mechanisms of TCP Suppression in an experimental Ruthenium-bearing single crystal nicke-base superalloy at $1100^{\circ} \mathrm{C} "$, Metallurgical and Materials Transactions A, Vol.39A, Issue 5, 1014-1025, May, 2008

[10] JMatPro website: http://www.thermotech.co.uk

[11] O. Lavigne, C. Ramusat, S. Drawin, P. Caron, D. Boivin, and J.-L. Pouchou: "Relationships between microstructural instabilities and mechanical behaviour in new genetation nickel-based single crystal superalloys", Superalloys 2004, Edited by K. A. Green, T. M. Pollock, H. Harada, T. E. Howson, R. C. Reed, J. J. Schirra and W. S. Walston, TMS, Warrendale PA, 2004, 667-675
[12] C. M. F. Rae, M. S. Hook and R. C. Reed: "The effect of TCP morphologies on the development of aluminize coated superalloys", Materials Science and Engineering A, vol. 3, 96A, 2005, 231-239 